\title{
Dietary supplementation with dried olive pomace in dairy cows modifies the composition of fatty acids and the aromatic profile in milk and related cheese
}

\author{
F. Castellani, A. Vitali, N. Bernardi, E. Marone, F. Palazzo, L. Grotta, and G. Martino ${ }^{1}$ \\ Facoltà di Bioscienze e Tecnologie Agroalimentari ed Ambientali, Università di Teramo, Teramo, Italy, 64100
}

\begin{abstract}
This study aimed to evaluate the effect of dietary integration of dried olive pomace (DOP), a by-product of olive oil separation, on nutritional and aromatic properties of milk and cheese. Twenty dairy cows were divided into 2 groups that were balanced for milk yield, parity, and days in milk. The control group was fed a conventional diet (20 kg of dry matter/head per day), whereas the experimental group (EG) received the conventional diet supplemented with DOP as $10 \%$ of dry matter. During the trial, milk yield was recorded and the samples of milk, cheese, total mixed rations, and DOP were collected and analyzed to determine the chemical-nutritional composition and aromatic profile. Atherogenic and thrombogenic indices were calculated on the basis of the fatty acid (FA) profile of milk and cheese. Data were analyzed according to the mixed model for milk yield and chemical composition, including cows nested within treatment as a random effect, whereas the general linear model was used for the analysis of cheese parameters. Differences were assessed by Tukey's test. The EG diet had a lower content of palmitic, stearic, and linoleic acids and a higher level of oleic acid compared with the control. Dietary DOP integration did not affect milk yield and composition with the exception of protein content, which was greater in EG and significantly affected by diet and period. Instead, period was found to be significant for fat and casein in both groups. Dietary supplementation with DOP modified the FA profile of milk and cheese. There was a decrease in short- and medium-chain FA, but significance was achieved only for palmitic acid. The stearic, isomer trans of oleic (in particular vaccenic acid), oleic, and isomer trans of linoleic acids significantly increased. Monounsaturated FA increased in EG milk and cheese and saturated FA were significantly lower,
\end{abstract}

Received March 20, 2017.

Accepted July 13, 2017.

${ }^{1}$ Corresponding author: gmartino@unite.it whereas no difference was marked between the groups regarding level of polyunsaturated FA. Supplementation with DOP reduced atherogenic and thrombogenic indices and increased conjugated linoleic acid in both milk and cheese. The free fatty acids, ketones, lactones, esters, and phenylalanine catabolites were increased in raw milk, whereas only leucine metabolism was affected by diet in pasteurized milk cheese at both 1 and $30 \mathrm{~d}$ of ripening. The present results pointed out that DOP supplementation may improve the nutritional and nutraceutical properties and modify the aroma of milk and derived cheese.

Key words: olive pomace, milk, cheese, fatty acid, aromatic profile

\section{INTRODUCTION}

Olive production is principally located in the Mediterranean area, which contributes to $76 \%$ of the total global production of olive oil. Spain, Italy, and Greece are the main producers of olive oil. The olive fruits (drupes) contain about 50\% water; the other 50\% is equally divided into oil (as ether extract; EE) and exhausted DM (Marone et al., 2003). Thus, after olive oil extraction, a large amount of hardly biodegradable OM comprising vegetation water (waste water) and pomace (crushed stone, skin, and pulp with a nonnegligible presence of oil) is produced.

Olive pomace shows a low CP content $(<10 \%$ of $\mathrm{DM}$ ), a high crude fiber content (up to $50 \%$ of DM), and up to $15 \%$ of EE (mainly oil); it is further characterized by a high level of UFA (mainly C18:1 cis-9, oleic acid; Molina-Alcaide and Yañez-Ruiz, 2008). Using olive pomace in animal nutrition is an interesting and sustainable alternative to its disposal because it may decrease the costs associated with animal feeding, thus valorizing a waste biomass. Moreover, the supplementation of the diet with olive pomace seems to be helpful in improving the quality of dairy products.

Several studies have tested dietary olive pomace supplementation in ruminant species, but they did not highlight any effects on production characteristics such 
as milk yield (Terramoccia et al., 2013; Zilio et al., 2014; Cibik and Keles, 2016) and growth rate (Owaimer et al., 2004; Awawdeh and Obeidat, 2013; Mele et al., 2014). On the other hand, to date only a few studies have reported the effect of dietary olive pomace supplementation on fatty acid (FA) composition and aromatic profile in milk and cheese. Chiofalo et al. (2004) reported a significant increase in UFA/SFA ratio and a decrease in atherogenic and thrombogenic indices of milk in ewes fed partly stoned olive cake. These findings were confirmed by other studies (Abbeddou et al., 2011b; Vargas-Bello-Pérez et al., 2013) in dairy ewes supplemented with olive pomace. These authors observed a decrease in short- and medium-chain FA proportion and an increase in oleic acid in milk.

Functionality and risks to human health posed by foods of animal origin are an increasing concern. Fats from ruminant products (milk, cheese, meat) are characterized by a category of FA that are positively correlated with human health (Mozaffarian et al., 2010; Dilzer and Park, 2012). Therefore, it is important to improve the understanding of the relationship between feeding management strategies and nutritional and nutraceutical properties of dairy products.

It is well known that diet, whether or not mediated by rumen metabolism (i.e., protected fats), can modify the aromatic profile of dairy products. Evidence supports the relationship between feeding management and aromatic profile in products of animal origin. Cows fed the conventional diet showed differences between aroma compounds of fresh milk compared with those fed pasture (Bendall, 2001). Cows (Cais-Sokolińska et al., 2011), ewes (Sympoura et al., 2009), and lambs (Elmore et al., 2005) fed diets enriched with UFA showed a significant change in volatile compounds in milk and cooked meat. To the best of our knowledge, only Caputo et al. (2015) have evaluated the effect of dietary supplementation with olive pomace (as 15\% of total DM) on the aromatic profile of cow milk and cheese indicating no effect after $15 \mathrm{~d}$ of treatment. The present study aimed to assess the effect of dietary dried olive pomace (DOP) supplementation on nutritional quality, FA composition, and aromatic profile of milk and produced cheese by dairy cows.

\section{MATERIALS AND METHODS}

The animals were managed according to Directive 2010/63/EU of the European Parliament (European Union, 2010) and Directive 86/609/EEC (European Economic Community, 1986), which deal with the protection of animals used for experimentation or other scientific purposes.

\section{DOP Production}

The DOP was obtained from 2 olive varieties (Gentile and Rustica) locally cultivated for high-quality oil production. The DOP was prepared in a traditional pressing mill where freshly harvested fruits were washed and precrushed. The obtained paste was forced and worked in a mill under 2 running millstones for about $20 \mathrm{~min}$. To facilitate the separation of oil, the paste was transferred to a malaxation machine for 20 to $25 \mathrm{~min}$ at 20 to $27^{\circ} \mathrm{C}$ before it was placed in a layer on fiber disks. Layers of disks and paste were stacked in piles and pressed to separate the pomace from the liquid fraction (vegetative water and oil) using hydraulic presses (400 atm). Then, the oil was separated from the water using a vertical centrifuge. To prevent successive spoilage, the fresh crude pomace was dried in a hot-air-heated chamber $\left(35^{\circ} \mathrm{C}\right)$. After 1 full day of milling, the fresh cake (about $4 \mathrm{t}$ ) was transferred in 20-cm-high layers placed in special plastic boxes $(55 \times 35 \times 29 \mathrm{~cm})$ that were largely used to handle, transport, and store the harvested olive fruits. The walls and the bottom of the boxes had holes and slots to allow air exchange. The temperature of the chamber was stabilized at around $35^{\circ} \mathrm{C}$. After the pomace drying, the boxes were moved into storage and maintained at room temperature.

\section{Experimental Design, Treatment, and Sample Collection}

The study was carried out on a commercial dairy farm located in central Italy. The farm included a mill for olive oil separation and a dairy factory for cheese production. Twenty healthy dairy cows (Holstein Friesian) were divided into 2 groups (10 animals each) and were balanced for milk yield, parity, and DIM (Table 1). The control group (CG) was fed a conventional diet (20 $\mathrm{kg}$ of $\mathrm{DM} /$ head per day as TMR), whereas the experimental group (EG) received the conventional diet supplemented with DOP as $10 \%$ of DM. The DOP was integrated into the experimental diet as a partial replacement of corn silage, alfalfa hay, sunflower meal, and wheat meal, obtaining a forage/concentrate ratio of 66:34 and 54:46 in the CG and EG diets, respectively.

Feeds were collected at the beginning, middle, and end of the trial. The TMR of the CG and EG diets were collected across the entire feeding alley in the morning and evening. The total amount collected at each time and for each group was mixed, and a final sample was taken. After drying the olive pomace, it was stored in boxes and sampled from the top, middle, and bottom. The total amount collected at each time was pooled, and a final sample was taken. Samples of feed were 
thereafter analyzed for chemical composition. Ingredients and chemical composition of the CG and EG diets and DOP are reported in Table 1.

The study lasted for $74 \mathrm{~d}$ and included a period of adaptation to the experimental diet. During the adaptation period, DOP was increased daily up to $2 \mathrm{~kg}$ of DM; this was achieved on d 14, which was considered time zero. The experimental period lasted for 60 d. During this period, milk yield was recorded once a week and individual milk samples were collected every 2 wk and then analyzed for their chemical composition. At the end of the treatment (d 60), individual milk of each group was first sampled for FA analysis. The remaining milk was pooled for each group as bulk milk and sampled before pasteurization for aromatic profile analysis.

Bulk milk obtained from each group was collected on the last day of the trial as described previously. It was pasteurized at $72^{\circ} \mathrm{C}$ for $15 \mathrm{~s}$, cooled to $38 \pm 1^{\circ} \mathrm{C}$, and transferred to the cheese-making container. Subsequently, starter bacteria $(200 \mathrm{~g} / 100 \mathrm{~L})$ were added to the milk, and it was kept at the same temperature for 30 min (acidification). Lactococcus lactis and Lactococcus lactis diacetyl (DEM3) and Streptococcus thermophilus (STA IDC15) starter cultures were used. Rennet (75\% chymosin and $25 \%$ pepsin; Clerici, Cadorago, Italy) was added $(15 \mathrm{~g} / 100 \mathrm{~kg})$ to the milk, and cheese coagulum was broken after $30 \mathrm{~min}$ of incubation.

The curd was packed into hoops, turned over a few times, and kept at $28^{\circ} \mathrm{C}$ until the $\mathrm{pH}$ reached a value of 5.3. After this, a $25 \% \mathrm{NaCl}$ water solution was used to salt the cheese in brine $(2 \mathrm{~h} / \mathrm{kg}$ of cheese). Thereafter, the cheese was stored in the ripening room at a controlled temperature $\left(10^{\circ} \mathrm{C}\right)$ and a relative humidity of $85 \%$. Cheese of each group was sampled at $1 \mathrm{~d}\left(\mathbf{T}_{1}\right)$ and $30 \mathrm{~d}\left(\mathbf{T}_{\mathbf{3 0}}\right)$ of ripening and was thereafter analyzed for chemical-nutritional composition and aromatic profile.

\section{Chemical Analysis of Feed, Milk, and Cheese}

The samples of TMR and DOP were analyzed for $\mathrm{DM}, \mathrm{CP}, \mathrm{EE}$, and ash according to AOAC International (1995). The NDF and ADF were determined using the method reported by Goering and Van Soest (1970).

Milk composition (fat, protein, casein, lactose, and urea) was determined by MilkoScan FT 6000 (Foss Integrator IMT; Foss, Hillerød, Denmark), and SCC was determined using a Fossomatic TM FC (Foss). Cheese moisture content and ash were determined according to AOAC International (2000), and fat was extracted according to Domagała et al. (2010) using a mix of chloroform and methanol (2:1, vol/vol). Milk lipid

Table 1. Group characteristics (mean \pm SD), ingredients, and nutrient composition of diets and dried olive pomace (DOP)

\begin{tabular}{|c|c|c|c|}
\hline \multirow[b]{2}{*}{ Item } & \multicolumn{2}{|c|}{ Diet } & \multirow[b]{2}{*}{ DOP } \\
\hline & Control & Experimental $^{1}$ & \\
\hline \multicolumn{4}{|l|}{ Animal parameters } \\
\hline Milk yield, kg & $26.96 \pm 2.10$ & $27.73 \pm 3.51$ & \\
\hline Parity, no. & $2.10 \pm 0.88$ & $2.30 \pm 0.82$ & \\
\hline DIM & $118 \pm 34$ & $121 \pm 42$ & \\
\hline \multicolumn{4}{|c|}{ Ingredient, $\mathrm{kg}$ of $\mathrm{DM} /$ head per day } \\
\hline Corn silage & 9.90 & 8.25 & \\
\hline Second-cut alfalfa hay & 3.96 & 3.08 & \\
\hline Corn grain meal & 3.34 & 4.27 & \\
\hline Soybean meal & 1.94 & 2.38 & \\
\hline Sunflower meal & 0.88 & 0.44 & \\
\hline Wheat meal & 0.44 & - & \\
\hline DOP & - & 2.00 & \\
\hline Vitamins and minerals & 0.45 & 0.45 & \\
\hline Total & 20.91 & 20.86 & \\
\hline \multicolumn{4}{|l|}{ Nutrient composition } \\
\hline DM, \% & 49.11 & 52.77 & 66.19 \\
\hline $\mathrm{CP}^{2} \%$ & 15.31 & 15.29 & 7.65 \\
\hline Ether extract, ${ }^{2} \%$ & 2.92 & 3.21 & 15.23 \\
\hline $\mathrm{NDF},{ }^{2} \%$ & 33.99 & 34.29 & 58.32 \\
\hline $\mathrm{ADF}^{2} \%$ & 19.81 & 20.40 & - \\
\hline Starch, ${ }^{2} \%$ & 26.56 & 26.52 & - \\
\hline $\mathrm{Ash}^{2} \%$ & 7.80 & 7.63 & - \\
\hline $\mathrm{NE}_{\mathrm{L}}$, milk $\mathrm{UFL}^{3} / \mathrm{kg}$ of $\mathrm{DM}$ & 0.92 & 0.90 & - \\
\hline
\end{tabular}


fraction was extracted according to the Röse-Gottlieb method (AOAC International, 2000). In both milk and cheese, $50 \mathrm{mg}$ of lipids was reconstituted with $5 \mathrm{~mL}$ of hexane containing C21:0 methyl ester as an internal standard (Sigma-Aldrich, St. Louis, MO), and $100 \mu \mathrm{L}$ of sodium methoxide in methanol (1:1 vol/vol) was used for methylation. Separation of FAME was performed by GC using a gas chromatograph (Focus GC; Thermo Scientific, Waltham, MA) equipped with a capillary column (CP88-select CB for FAME; $100 \mathrm{~m} \times$ $0.25 \mathrm{~mm}$ i.d., $0.25 \mu \mathrm{m}$ film thickness; Agilent Technologies, Santa Clara, CA) and a flame ionization detector. Hydrogen was used as a carrier gas. The initial holding temperature was $55^{\circ} \mathrm{C}$ for $1 \mathrm{~min}$; then it was increased to $170^{\circ} \mathrm{C}$ at a rate of $10^{\circ} \mathrm{C} / \mathrm{min}$ and held for $30 \mathrm{~min}$. The final temperature of $215^{\circ} \mathrm{C}$ was reached at a rate of $2^{\circ} \mathrm{C} / \mathrm{min}$ and was held for $4 \mathrm{~min}$.

Individual FAME were identified by comparing the retention time of a standard mixture (FIM-FAME7-Mix; Matreya LLC, Pleasant Gap, PA), individual trans-11 C18:1 and individual cis-9,trans-11 C18:2 (Matreya LLC), and chromatograms per the method followed by Kramer et al. (2008). Peak areas were quantified using ChromeCard software, and the relative value of each individual FA was expressed as a percentage of the total FA.

Atherogenic and thrombogenic indices (AI and TI, respectively) were determined in milk and cheese using the formula proposed by Ulbricht and Southgate (1991):

$$
\mathrm{AI}=\frac{(\mathrm{C} 12: 0+4 \times \mathrm{C} 14: 0+\mathrm{C} 16: 0)}{\left[\sum \mathrm{MUFA}+\sum \operatorname{PUFA}(\mathrm{n}-3 ; \mathrm{n}-6)\right]}
$$

and

$$
\mathrm{TI}=\frac{(\mathrm{C} 14: 0+\mathrm{C} 16: 0+\mathrm{C} 18: 0)}{\left\{\begin{array}{l}
{\left[0.5 \times \sum \operatorname{MUFA}\right]+\left[0.5 \times \sum \operatorname{PUFA}(\mathrm{n}-6)\right]} \\
+\left[3 \times \sum \operatorname{PUFA}(\mathrm{n}-3)\right]+(\mathrm{n}-3 / \mathrm{n}-6)
\end{array}\right\}}
$$

Desaturation index (DI) was calculated using the formula suggested by Mele et al. (2007):

$$
\mathrm{DI}=\frac{\mathrm{C} 14: 1 \text { cis }-9}{\mathrm{C} 14: 0+\mathrm{C} 14: 1 \text { cis }-9} .
$$

\section{Volatile Compounds Analysis by Solid-Phase Microextraction and GC-MS}

Extraction of volatile compounds from milk and cheese samples was performed by solid-phase microex- traction (SPME), and GC-MS analysis was performed with a gas chromatograph (Clarus 580; Perkin Elmer, Waltham, MA) coupled with a mass spectrometer (SQ8S; Perkin Elmer). The gas chromatograph was equipped with an Elite-5MS column (length $\times$ internal diameter: $30 \times 0.25 \mathrm{~mm}$; film thickness: $0.25 \mu \mathrm{m}$; Perkin Elmer). Ten milliliters of milk or $5 \mathrm{~g}$ of grated cheese was mixed with 5 and $10 \mathrm{~mL}$ of saturated $\mathrm{NaCl}$ solution $(360 \mathrm{~g} / \mathrm{L})$, respectively, and then $10 \mu \mathrm{L}$ of internal standard solution (4-methyl-2-heptanone; 10 $\mathrm{mg} / \mathrm{kg}$ in ethanol) was added.

The vials were sealed with a polytetrafluoroethylenesilicone septum (Supelco, Bellefonte, PA) and stirred at $60^{\circ} \mathrm{C}$. Volatile compounds were extracted from the headspace with a divinybenzene-carboxen-polydimethylsiloxane SPME fiber (length: $1 \mathrm{~cm}$; film thickness: $50 / 30 \mu \mathrm{m}$; Supelco), directly exposed for $30 \mathrm{~min}$ for milk and $1 \mathrm{~h}$ for cheese samples at the same temperature and agitation conditions. In the tests no significant differences were observed when the fiber was exposed after 15 or 30 min of sample stirring; thus, equilibration of the vial headspace was not performed (OzturkogluBudak et al., 2016).

After adsorption time, volatile compounds extracted by the SPME fiber were thermally desorbed into the gas chromatograph injector splitless mode for $1 \mathrm{~min}$ at $250^{\circ} \mathrm{C}$. The oven temperature was held at $50^{\circ} \mathrm{C}$ for $1 \mathrm{~min}$, increased at a rate of $3^{\circ} \mathrm{C} / \mathrm{min}$ up to $200^{\circ} \mathrm{C}$ and held for $1 \mathrm{~min}$, and then increased from $200^{\circ} \mathrm{C}$ to $250^{\circ} \mathrm{C}$ at $15^{\circ} \mathrm{C} / \mathrm{min}$ and held for $15 \mathrm{~min}$. Helium was used as a carrier gas at a flow rate of $1 \mathrm{~mL} / \mathrm{min}$. The mass spectrometer operated in electronic impact ionization mode at $70 \mathrm{eV}$, and data were collected in full scan mode, with a scan time of $0.2 \mathrm{~s}$ over a mass range of 35 to 350 . Source and interface temperature were held at $250^{\circ} \mathrm{C}$. Volatile compounds were identified by comparison with mass spectra of a library database (NIST Mass Spectral library, Search Program version 2.0, National Institute of Standards and Technology, U.S. Department of Commerce, Gaithersburg, MD) and by comparing the eluting order with Kovats indices. Quantification was carried out integrating the peak areas of a target ion for each compound. The volatile composition was expressed in arbitrary units (AU; target ion area $\left.\times 10^{-3}\right)$.

\section{Statistical Analysis}

Milk yield and chemical composition were analyzed according to a mixed model using PROC MIXED of SAS (version 9.0; SAS Institute Inc., Cary, NC) with diet, period (week for milk yield and 2 wk for chemical composition), and diet $\times$ period as fixed factors. The random effect of cows nested within the treatment was included in the model. The FA composition of individ- 
Table 2. Fatty acid profile of dried olive pomace (DOP) and diets

\begin{tabular}{|c|c|c|c|c|}
\hline \multirow[b]{2}{*}{ Fatty acid ${ }^{1}$} & \multirow[b]{2}{*}{ DOP } & \multicolumn{2}{|c|}{ Diet } & \multirow[b]{2}{*}{$P$-value } \\
\hline & & Control & Experimental $^{2}$ & \\
\hline C16:0 & 12.53 & $14.05 \pm 0.35$ & $13.55 \pm 0.24$ & 0.08 \\
\hline C18:0 & 3.22 & $3.29 \pm 0.08$ & $2.85 \pm 0.10$ & $<0.05$ \\
\hline $\mathrm{C} 18: 1$ cis- 9 & 69.56 & $23.74 \pm 0.37$ & $39.12 \pm 0.70$ & $<0.001$ \\
\hline C18:2 cis-9,cis-12 & 9.27 & $45.07 \pm 0.78$ & $39.48 \pm 0.48$ & $<0.001$ \\
\hline C18:3 cis-9,cis-12,cis-15 & 0.68 & $3.18 \pm 0.63$ & $2.79 \pm 0.18$ & 0.19 \\
\hline
\end{tabular}

ual milk samples collected on the last day of the trial was analyzed according to PROC MIXED with diet as a fixed effect plus cows nested within treatment. Bulk milk aromatic profile was analyzed by 1-way ANOVA, including diet as a fixed factor. Chemical and FA composition and aromatic profile of cheese were analyzed by PROC GLM, including diet, time of ripening, and their interactions as fixed effects. Separation of means was assessed by Tukey's test, and differences were considered significant if $P<0.05$. Results were reported as least squares means \pm standard error of the mean.

\section{DOP and Diet}

\section{RESULTS}

The FA profile of DOP and diets is shown in Table 2. The most abundant FA in DOP was oleic acid (C18:1 cis-9). Palmitic (C16:0) and linoleic (C18:1 cis-9,cis-12) acids were the other acids that were also present, whereas stearic (C18:0) and linolenic (C18:3 cis-9, cis12, cis-15) acids were the FA less present in DOP. The EG diet showed a significantly lower content of stearic and linoleic acids compared with the CG diet, whereas we observed an increased content of oleic acid in the EG diet as a consequence of its high DOP content.

\section{Nutritional Composition of Milk and Cheese}

Milk yield recorded during the experimental period was not affected by diet, period, and diet $\times$ period in- teraction $(P>0.05)$. Dietary DOP integration did not affect milk composition (Table 3 ) with the exception of protein content, which was affected by $\operatorname{diet}(P<0.05)$ and period $(P<0.05)$ and was greater in EG than in CG. Fat content did not differ between the groups. Instead, period affected fat $(P<0.05)$ and casein $(P<$ $0.05)$ contents in both groups. Milk urea content was not different between groups, and values were in the recommended range (23-35 mg/100 mL; Mariani et al., 1992). The SCC did not differ during the trial $(P>$ $0.05)$ conducted between the groups.

Chemical compositions of $T_{1}$ cheese and $T_{30}$ cheese are reported in Table 4. Many chemical parameters were affected by diet $\times$ period interactions. Moisture content was lower $(P<0.001)$ in the $\mathrm{EG}$ diet at $\mathrm{T}_{1}$ compared with the $\mathrm{CG}$ diet and, as expected, decreased significantly after $30 \mathrm{~d}$ of ripening in both groups. No differences in fat content were observed between groups at both $\mathrm{T}_{1}$ and $\mathrm{T}_{30}$. Fat concentration decreased significantly in both groups $(P<0.001)$ from $\mathrm{T}_{1}$ to $\mathrm{T}_{30}$.

The FA composition of individual milk samples, which were collected at the end of the trial, and the corresponding cheese at $\mathrm{T}_{30}$ is shown in Table 5. Results for the FA profile recorded in $\mathrm{T}_{1}$ cheese were not reported because no statistical difference was detected compared with $\mathrm{T}_{30}$ cheese. In light of this result, only data for $\mathrm{T}_{30}$ cheese (which corresponds to the marketing time) are shown. Inclusion of DOP modified the FA profile of milk and cheese. The major changes involved

Table 3. Effect of dried olive pomace supplementation on milk chemical characteristics

\begin{tabular}{|c|c|c|c|c|c|}
\hline \multirow[b]{2}{*}{ Item } & \multicolumn{2}{|c|}{ Diet } & \multirow[b]{2}{*}{ SEM } & \multicolumn{2}{|c|}{$P$-value } \\
\hline & Control & Experimental $^{1}$ & & Diet & Period \\
\hline Fat, $\%$ & 3.41 & 3.66 & 0.10 & 0.09 & $<0.001$ \\
\hline Protein, \% & 3.33 & 3.72 & 0.05 & $<0.05$ & $<0.05$ \\
\hline Casein, \% & 2.63 & 2.77 & 0.14 & 0.18 & $<0.001$ \\
\hline Lactose, \% & 4.76 & 4.62 & 0.17 & 0.15 & 0.37 \\
\hline Urea, mg/100 mL & 32.07 & 30.53 & 0.73 & 0.14 & 0.82 \\
\hline $\mathrm{SCC}, \times 10^{3}$ cells $/ \mathrm{mL}$ & 300 & 365 & 61.81 & 0.46 & 0.83 \\
\hline
\end{tabular}

${ }^{1}$ The experimental group was fed the conventional diet supplemented with $2 \mathrm{~kg}$ (DM basis) of dried olive pomace for $60 \mathrm{~d}$. 
Table 4. Chemical composition of cheese recorded at $1\left(\mathrm{~T}_{1}\right)$ and $30\left(\mathrm{~T}_{30}\right)$ d of ripening

\begin{tabular}{|c|c|c|c|c|c|c|c|}
\hline \multirow[b]{3}{*}{ Item } & \multicolumn{3}{|c|}{$\mathrm{T}_{1}$} & \multicolumn{3}{|c|}{$\mathrm{T}_{30}$} & \multirow{3}{*}{$\begin{array}{c}P \text {-value } \\
\text { Diet } \times \text { period }\end{array}$} \\
\hline & \multicolumn{2}{|c|}{ Diet } & \multirow[b]{2}{*}{ SEM } & \multicolumn{2}{|c|}{ Diet } & \multirow[b]{2}{*}{ SEM } & \\
\hline & Control & Experimental $^{1}$ & & Control & Experimental & & \\
\hline DM & $37.94^{\mathrm{a}, \mathrm{A}}$ & $42.71^{\mathrm{b}, \mathrm{A}}$ & 1.09 & $49.75^{\mathrm{B}}$ & $48.94^{\mathrm{B}}$ & 0.93 & $* * *$ \\
\hline Fat, $\%$ of DM & $37.31^{\mathrm{A}}$ & $39.06^{\mathrm{A}}$ & 1.08 & $32.05^{\mathrm{B}}$ & $32.86^{\mathrm{B}}$ & 1.22 & $* * *$ \\
\hline Ash & 3.63 & 3.93 & 0.43 & 4.41 & 4.44 & 0.54 & NS \\
\hline
\end{tabular}

palmitic, stearic, oleic, trans isomers of oleic (in particular vaccenic acid), linoleic, and CLA isomer (C18:2 cis-9,trans-11 and C18:2 trans-10,cis-12) acids.

Among single short- and medium-chain FA, only palmitic acid was lower $(P<0.001)$ in EG compared with $\mathrm{CG}$. On the other hand, stearic, trans isomers of oleic
(C18:1 trans-9 and C18:1 trans-11), oleic, rumenic, CLA trans-10,cis-12, and long-chain FA were greater $(P<0.05)$ in milk and cheese produced by cows supplemented with DOP.

Supplementation with DOP produced an increase in MUFA $(P<0.001)$, mainly because of the great amount

Table 5. Fatty acid composition of milk at the end of the trial and after $30 \mathrm{~d}$ of ripening in the corresponding cheese

\begin{tabular}{|c|c|c|c|c|c|c|c|c|}
\hline \multirow[b]{3}{*}{ Fatty acid ${ }^{1}$} & \multicolumn{4}{|c|}{ Milk } & \multicolumn{4}{|c|}{ Cheese } \\
\hline & \multicolumn{2}{|r|}{ Diet } & \multirow[b]{2}{*}{ SEM } & \multirow[b]{2}{*}{$P$-value } & \multicolumn{2}{|c|}{ Diet } & \multirow[b]{2}{*}{ SEM } & \multirow[b]{2}{*}{$P$-value } \\
\hline & Control & Experimental $^{2}$ & & & Control & Experimental & & \\
\hline $\mathrm{C} 4: 0$ & 2.81 & 2.57 & 0.09 & $\mathrm{NS}$ & 2.91 & 2.64 & 0.17 & NS \\
\hline C6:0 & 2.15 & 1.95 & 0.07 & NS & 2.27 & 2.06 & 0.14 & NS \\
\hline C8:0 & 1.40 & 1.30 & 0.04 & NS & 1.32 & 1.17 & 0.09 & NS \\
\hline C10:0 & 3.97 & 3.70 & 0.13 & NS & 3.67 & 3.50 & 0.20 & NS \\
\hline C11:0 & 0.41 & 0.27 & 0.09 & NS & 0.29 & 0.23 & 0.05 & NS \\
\hline C12:0 & 5.10 & 4.65 & 0.17 & NS & 4.72 & 4.38 & 0.18 & NS \\
\hline C13:0 & 0.19 & 0.18 & 0.02 & NS & 0.18 & 0.20 & 0.06 & NS \\
\hline C14:0 & 14.24 & 13.56 & 0.24 & NS & 13.57 & 13.29 & 0.27 & NS \\
\hline C14:1 & 1.73 & 1.54 & 0.13 & NS & 1.43 & 1.44 & 0.06 & NS \\
\hline C15:0 & 1.61 & 1.58 & 0.10 & NS & 1.52 & 1.61 & 0.03 & NS \\
\hline C15:1 & 0.20 & 0.18 & 0.01 & NS & 0.19 & 0.16 & 0.03 & NS \\
\hline C16:0 & 35.43 & 32.87 & 0.65 & $* * *$ & 35.48 & 32.74 & 0.67 & $* * *$ \\
\hline C16:1 & 1.80 & 1.55 & 0.13 & NS & 1.80 & 1.53 & 0.04 & $* * *$ \\
\hline C17:0 & 0.52 & 0.54 & 0.15 & NS & 0.53 & 0.55 & 0.02 & NS \\
\hline C17:1 & 0.23 & 0.20 & 0.02 & NS & 0.21 & 0.17 & 0.03 & NS \\
\hline C18:0 & 6.25 & 7.87 & 0.47 & $*$ & 6.24 & 7.20 & 0.24 & $* * *$ \\
\hline C18:1 trans-9 & 0.21 & 0.38 & 0.02 & $* * *$ & 0.24 & 0.47 & 0.02 & $* * *$ \\
\hline C18:1 trans-11 & 0.67 & 1.10 & 0.05 & $* * *$ & 0.79 & 1.19 & 0.03 & $* * *$ \\
\hline $\mathrm{C} 18: 1$ cis-9 & 14.98 & 17.62 & 0.43 & $* *$ & 15.35 & 17.98 & 0.47 & $* * *$ \\
\hline $\mathrm{C} 18: 2$ cis-9, cis-12 & 1.87 & 1.86 & 0.06 & NS & 1.80 & 1.98 & 0.11 & NS \\
\hline $\mathrm{C} 18: 2$ trans -10, cis-12 & 0.15 & 0.23 & 0.03 & $*$ & 0.21 & 0.28 & 0.01 & $*$ \\
\hline C18:2 cis-9,trans-11 & 0.46 & 0.56 & 0.01 & $* * *$ & 0.55 & 0.69 & 0.02 & $* * *$ \\
\hline $\mathrm{C} 18: 3$ cis-9,cis-12,cis-15 & 0.21 & 0.22 & 0.01 & NS & 0.21 & 0.23 & 0.01 & NS \\
\hline $\mathrm{C} 20: 3$ & 0.10 & 0.10 & 0.01 & NS & 0.11 & 0.12 & 0.01 & NS \\
\hline Short chain ${ }^{3}$ & 10.69 & 9.79 & 0.29 & NS & 10.18 & 9.37 & 0.56 & NS \\
\hline Medium chain ${ }^{4}$ & 60.86 & 56.69 & 0.76 & $* * *$ & 59.72 & 56.12 & 0.42 & $* * *$ \\
\hline Long chain ${ }^{5}$ & 26.66 & 31.80 & 0.72 & $* * *$ & 27.33 & 32.19 & 0.88 & $* * *$ \\
\hline
\end{tabular}

${ }^{1}$ Expressed as a percentage of total FA.

${ }^{2}$ The experimental group was fed the conventional diet supplemented with $2 \mathrm{~kg}$ (DM basis) of dried olive pomace for $60 \mathrm{~d}$.

${ }^{3} \mathrm{C} 4: 0$ to $\mathrm{C} 10: 0$

${ }^{4} \mathrm{C} 11: 0$ to $\mathrm{C} 16: 1$.

${ }^{5} \mathrm{C} 17: 0$ to $\mathrm{C} 20: 3$.

${ }^{*} P<0.05 ;{ }^{* *} P<0.01 ;{ }^{* * *} P<0.001$. 
Table 6. Aggregated fatty acids and healthy indices observed in individual milk at the end of the trial and after $30 \mathrm{~d}$ of ripening in the corresponding cheese

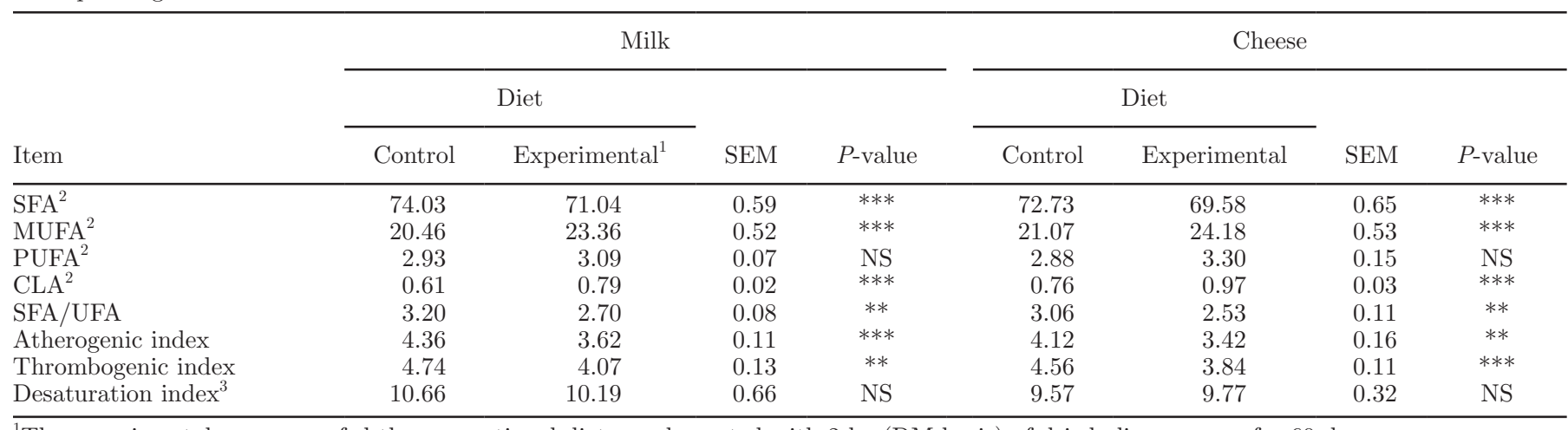

${ }^{1}$ The experimental group was fed the conventional diet supplemented with $2 \mathrm{~kg}$ (DM basis) of dried olive pomace for $60 \mathrm{~d}$.

${ }^{2}$ Expressed as a percentage of total FA.

${ }^{3}$ Desaturation index (cis-9 14:1/14:0 + cis-9 14:1).

** $P<0.01 ; * * * P<0.001$.

of oleic acid, and a decrease in SFA $(P<0.001)$, whereas no differences were observed for PUFA. The SFA/UFA ratio for both milk and cheese was lower $(P<0.01)$ in EG compared with CG. As a consequence, atherogenic and thrombogenic indices were reduced $(P<0.01)$ in EG milk and cheese. Finally, DOP supplementation was associated with an increased $(P<0.001)$ CLA content in milk and corresponding cheese, whereas no differences were observed for desaturation index in both milk and cheese (Table 6).

\section{Aromatic Profile of Milk and Cheese}

Several chemical families of volatile compounds from lipolysis and proteolysis catabolism were detected in raw milk and cheese of $\mathrm{CG}$ and EG. In raw milk, free FA (FFA; 12,491 vs. 26,223 AU for CG and EG, respectively), esters (783 vs. 1,053 AU for CG and EG, respectively), lactones (445 vs. $890 \mathrm{AU}$ for $\mathrm{CG}$ and $\mathrm{EG}$, respectively), and ketones (767 vs. 2,395 AU for CG and EG, respectively) were higher $(P<0.05)$ in EG milk compared with CG milk. However, no differences for aldehydes were found between the 2 groups (Figure 1). Among lactones, $\gamma$-lactones (43 vs. 69 AU for CG and EG, respectively) were higher $(P<0.05)$ in EG than in CG, whereas $\delta$-lactones (775 vs. 398 AU for CG and EG, respectively) decreased in EG milk compared with CG milk (data not shown). Regarding proteolysis, only Phe catabolites were detected in raw milk, and they were higher $(P<0.001)$ in EG than in CG.

Families of volatile compounds detected in $\mathrm{T}_{1}$ cheese and $\mathrm{T}_{30}$ cheese of $\mathrm{CG}$ and $\mathrm{EG}$ are shown in Figure 2. Regarding lipolysis, FFA, esters, lactones, ketones, and aldehydes were detected in cheese of both groups, whereas Phe, Leu, and Met catabolites were observed from proteolysis.
The results highlighted an increase $(P<0.05)$ in all classes of volatile compounds except esters and aldehydes during aging in both groups, indicating a ripening effect, although no differences were seen between the 2 groups at both $\mathrm{T}_{1}$ and $\mathrm{T}_{30}(P>0.05)$. The only exception was reported for Leu catabolites, which were higher at both $\mathrm{T}_{1}(P<0.01)$ and $\mathrm{T}_{30}(P<0.001)$ in EG compared with $\mathrm{CG}$.

\section{DISCUSSION}

Chemical composition of DOP, in particular protein content, in the current study was different from (Molina-Alcaide and Yañez-Ruiz, 2008; Terramoccia et al., 2013) or similar to (Sadeghi et al., 2009) that reported in other studies. The NDF of DOP was high mainly because of the presence of lignin in the stone, but it did not affect the NDF content of the EG diet. The high variability of DOP depends on several factors that are difficult to control, such as cultivar, year of production, olive maturation, and oil extraction method. The DOP integrated at $10 \%$ of DM did not modify the overall chemical composition of the EG diet compared with the CG diet, indicating that it may be used in cow diets at this concentration.

Milk yield was not affected by dietary DOP supplementation. This finding agrees with the results of other researchers who assessed the effect of diet integration (about 15\% of DM) of dried stoned olive pomace for 40 $\mathrm{d}$ in cows (Zilio et al., 2014) and buffalo (Terramoccia et al., 2013).

Milk protein content was influenced by dietary DOP integration. This result was unexpected and did not agree with other studies that reported no modification of protein content when ewes (Abbeddou et al., 2011b) and cows (Zilio et al., 2014) were fed olive pomace. 
非氺

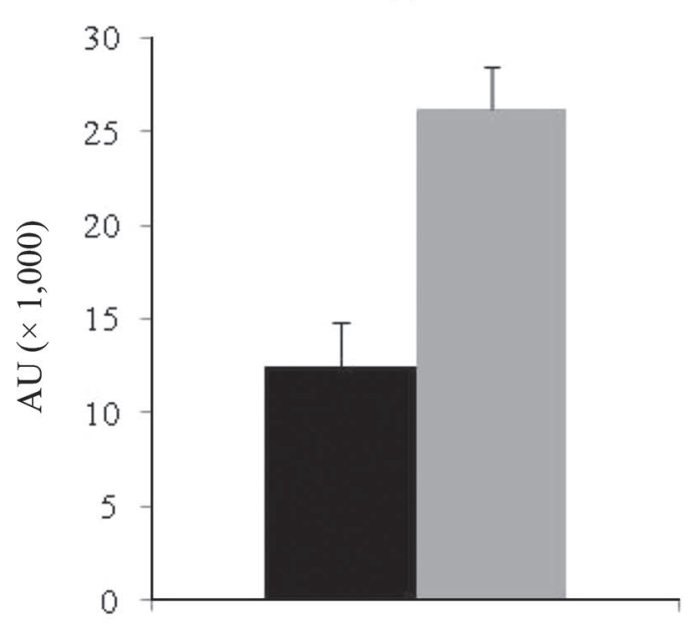

FFA

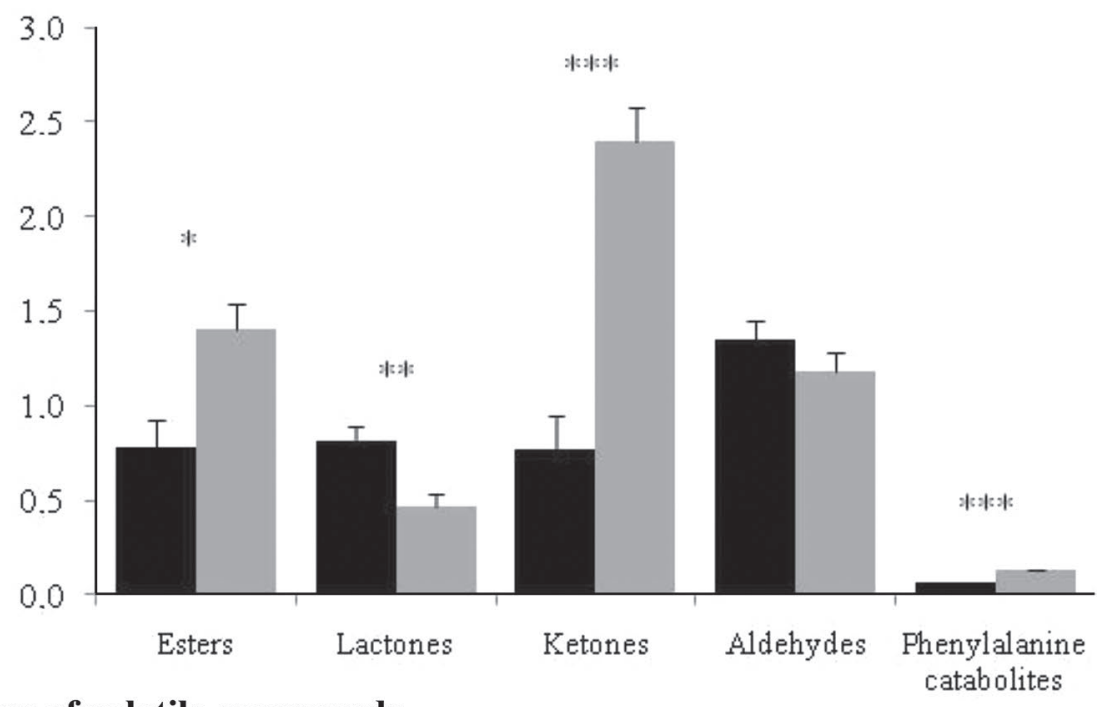

Class of volatile compounds

Figure 1. Classes of volatile compounds (LSM \pm SEM) detected in raw milk of cows fed the conventional diet (black bars) and a conventional diet supplemented with $2 \mathrm{~kg}(\mathrm{DM})$ of dried olive pomace (gray bars). FFA = free fatty acids. ${ }^{*} P<0.05 ;{ }^{* *} P<0.01 ; * * * P<0.001$.

Although diets were isoenergetic and isoproteic, EG cows received a lower amount of forage compared with CG cows, and the difference in the forage/concentrate ratio of the diets could be associated with the increased protein yield (Jenkins and McGuire, 2006). Moreover, Pallara et al. (2014) evaluated the effect of olive pomace
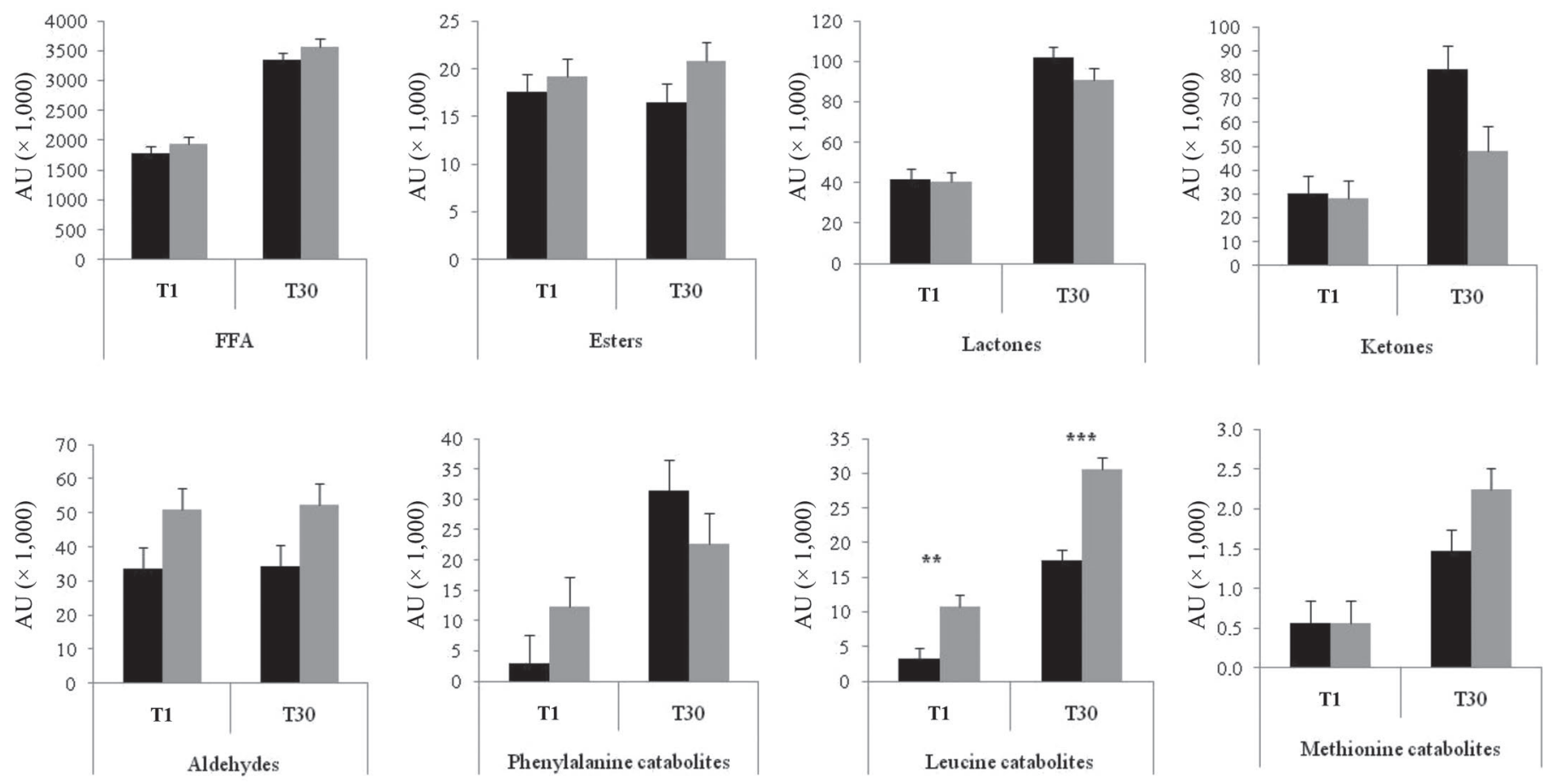

\section{Class of volatile compounds}

Figure 2. Classes of volatile compounds (LSM \pm SEM) detected in pasteurized-milk cheese obtained from milk produced by cows fed the conventional diet (black bars) and a conventional diet supplemented with $2 \mathrm{~kg}(\mathrm{DM})$ of dried olive pomace (gray bars). FFA = free fatty acids; $\mathrm{T} 1=1 \mathrm{~d}$ of ripening; T30 $=30 \mathrm{~d}$ of ripening. ${ }^{* *} P<0.01 ;{ }^{* * *} P<0.001$. 
on rumen microbial communities in an in vitro study and highlighted that the inclusion of olive pomace stimulated rumen VFA production. This finding suggests that dietary olive pomace integration may modify rumen microbial activity and protein content in milk, and further studies are needed to clarify this behavior.

Chemical composition of $T_{1}$ and $T_{30}$ cheese was not affected by dietary integration with DOP. This result is in agreement with those obtained in dairy sheep (Abbeddou et al., 2011a; Branciari et al., 2014).

The results of the present study showed a positive effect of DOP utilization on FA profile of milk and cheese. According to Nudda et al. (2005), the FA composition found in cheese reflects the composition observed in milk. This suggests that the improvement in nutritional quality achieved in milk as a consequence of DOP supplementation is thereafter maintained in the relatively fresh and aged cheese.

Dietary DOP integration reduced short- and medium-chain FA, but only palmitic acid was significantly lower in EG milk and cheese. Short- and medium-chain FA are synthesized completely de novo and partially by the mammary gland starting from acetate and BHB, respectively, produced in the rumen (Lock and Bauman, 2004). Other studies reported that supplementation with long-chain FA negatively affected the de novo synthesis of short- and medium-chain FA in the mammary gland (Shingfield et al., 2013). Medium-chain FA are responsible for increasing the concentration of low-density lipoprotein cholesterol in blood when it is not associated with the correct level of linoleic acid (Sundram et al., 2003). The reduction of medium-chain FA, in particular for palmitic acid, could improve the nutritional quality of milk and other dairy products.

As expected, DOP positively affected the oleic acid level in milk and cheese. In addition to the high content of oleic acid in DOP, this result might be related to the desaturation of stearic acid occurring in the mammary gland by $\Delta^{9}$-desaturase (Loften et al., 2014), encoded by the stearoyl coenzyme A desaturase gene (Smith et al., 2006). This mechanism was reported in dairy sheep (Vargas-Bello-Pérez et al., 2013) and buffalo (Terramoccia et al., 2013) fed dietary olive pomace supplements. However, C14:1/C14:0 ratio, considered an index of $\Delta^{9}$-desaturation in the mammary gland (Mele et al., 2007), did not differ between the groups, suggesting that the increase in oleic acid is related more to diet than to $\Delta^{9}$-desaturase activity.

Previous studies have investigated the effect of olive pomace or tannins on the rumen microbial community, in particular the Butyrivibrio genus and Butyrivibrio proteoclasticus, which are responsible for hydrogenation of UFA and the reduction of C18:1 to C18:0, respectively. Olive pomace and tannins negatively affected the Butyrivibrio genus and B. proteoclasticus activity and slowed the hydrogenation of oleic and linoleic intermediates in ewes (Pallara et al., 2014) and lambs (Vasta et al., 2010), suggesting a partial escape of biohydrogenation (BH) intermediates from the rumen (Sinclair, 2007). Our results are consistent with previous studies that highlighted that dietary supplementation with vegetables with high oil content produced a higher level of C18:0, C18:1, C18:1 trans-11, and C18:2 cis-9,trans-11 in both goats (Mele et al., 2008) and cows (Dhiman et al., 2000).

Stearic acid, the final product of $\mathrm{BH}$ of dietary MUFA and PUFA (Mosley et al., 2002), increased in EG milk and cheese, suggesting the complete saturation of double bonds in long-chain FA during microbial $\mathrm{BH}$. Our results agree with previous studies showing that the concentration of stearic acid in milk and dairy products increased when diets contained a high level of unsaturated C18 FA (Gómez-Cortés et al., 2008; Moate et al., 2014). On the other hand, dietary supplementation with DOP seems to promote the secretion of $\mathrm{BH}$ intermediates (vaccenic acid in particular) in milk, leading to an increase in milk CLA isomers.

Trans isomers of oleic acid (mainly vaccenic acid) and rumenic acid content in milk are regulated by stearoyl coenzyme A desaturase activity in mammary tissue. In particular, rumenic acid (cis-9,trans-11 C18:2) has 2 origin pathways. The first is the partial rumen $\mathrm{BH}$ of linoleic acid, which is responsible for the production of a small proportion of CLA secreted in milk (Chilliard and Ferlay, 2004). The second is its endogenous synthesis in the mammary gland starting from vaccenic acid (Lock and Bauman, 2004), which is responsible for about $60 \%$ of rumenic acid secretion in cow milk (Griinari et al., 2000; Mosley et al., 2006).

Rumenic acid and CLA trans-10, cis-12 are the predominant CLA in milk, and their concentrations in both milk and cheese were greater in EG compared with CG. Conjugated linoleic acid is reported to have an important role in the functionality of the mammary gland, mediated by its antioxidant activity. Recent studies showed that CLA isomers protect bovine mammary epithelial cells from lipoperoxidation (Basiricò et al., 2015), and they mitigate the level of the reactive oxygen species better than other FA studied (Basiricò et al., 2017). Ruminant products are the primary dietary source of CLA for humans. The benefits of CLA for human health are related to their potential activity in slowing the development of atherosclerosis (Lock et al., 2004), reducing accumulation of body fat (Evans et al., 2002), enhancing bone mineralization (Platt et al., 2007), modulating the immune system (Song et al., 2005), and influencing glucose and lipid metabolism (Belury et al., 2003). 
Finally, MUFA and PUFA content in milk and cheese was positively influenced by dietary DOP integration, which negatively affected SFA level. As a consequence, SFA/UFA ratio and atherogenic and thrombogenic indices decreased in the EG. In light of this, it could be argued that dietary DOP supplementation may be of help in increasing nutritional value and health functionality of milk and related dairy products.

Regarding aromatic profile, some classes of volatile compounds derived from lipolytic and proteolytic processes seem to develop differently in raw milk and pasteurized-milk cheese, as seen between the 2 groups. In raw milk, FFA, ketones, lactones, esters, and Phe catabolism were influenced by DOP supplementation. Production of FFA may be attributed to the activity of esterase and endogenous lipoprotein lipase, which naturally are present in raw milk (McSweeney and Sousa, 2000). A suggested pathway for the development of FFA is the high content of SCC. In our study, although the SCC level was higher in EG, the differences were not significant and probably could not support this hypothesis. Therefore, further studies are necessary to better understand the mechanisms involved in FFA development. Moreover, the higher content of FFA in EG liberated through lipolysis may influence the production of ketones, originating from FFA oxidation to $\beta$-ketoacids and subsequent decarboxylation.

Supplementation with DOP positively influences the development of $\gamma$-lactones. The accumulation of these compounds in milk is closely related to the dietary integration of oleic acid. In particular, oleic acid is indicated as the precursor of 10-hydroxy stearic acid in the rumen that is transformed in $\gamma-12: 0$ by $\beta$-oxidation in the mammary gland (Jenkins et al., 2006).

The high content of oleic acid in the EG diet due to DOP integration may account for the decrease of $\delta$-lactones in milk. Indeed, ruminal production of acetate that represents the precursor of lactones in the mammary gland (Walker et al., 1968) is reduced by dietary UFA (Griinari et al., 1998) through the inhibition of fiber digestion.

Esters are sometimes present in the raw milk of ruminants (Moio et al., 1993), and their biosynthesis occurs by activity of lactic acid bacteria, which are common microorganisms in raw milk and cheese. Esters, especially ethyl esters, are responsible for the sweet, floral, and fruity notes of cheese, and their contribution to the flavor of dairy products depends on their concentration: they positively contribute to the overall flavor balance at a low concentration, whereas they are considered offflavors at a high level (Liu et al., 2004). Moreover, these compounds contribute to the development of the aromatic profile in dairy products, minimizing the bitter aroma conferred by FFA (Curioni and Bosset, 2002).
Integration of DOP did not affect the content of aldehyde, which is a common product of decomposition of hydroperoxides developed by the oxidation of UFA (Day, 1966; Esterbauer, 1982). Our results are in agreement with Sympoura et al. (2009), who did not highlight differences in aldehyde content in cheese when extruded linseed was integrated into the cow diet.

Phenylalanine is the only AA detected in raw milk, and its metabolism seems to be influenced by diet. The greater development of Phe catabolites in EG probably is associated with the higher protein content reported in milk.

Finally, among families of volatile compounds from lipolysis and proteolysis detected in pasteurized-milk cheese, only Leu metabolism was affected by DOP supplementation at both $\mathrm{T}_{1}$ and $\mathrm{T}_{30}$. Generally, Leu is the most abundant $\mathrm{AA}$ in cheese, and its catabolism determines the production of important flavor compounds for the development of cheese aroma (Smit, 2004). Various microorganisms used in cheese-making, such as those belonging to the genera Lactococcus, Lactobacillus, Streptococcus, and Propionibacterium, are able to convert Leu into several flavor compounds. However, further study is needed to better clarify the effect of DOP on the development of Leu catabolites during cheese ripening.

\section{CONCLUSIONS}

The present results show that DOP utilization in the diet of lactating dairy cows may modify the quality of dairy products. The increased UFA (oleic acid, vaccenic acid, and CLA) and decreased SFA (short- and medium-chain FA until palmitic acid) suggests a positive role of DOP in improving the nutritional and nutraceutical properties of milk and corresponding cheese. As a consequence, the aromatic profile of dairy products, especially raw milk, also was modified by DOP integration. Therefore, it is necessary to verify whether these changes may have any effect on consumer acceptability. The substitution of conventional feeds with waste biomasses produced by agroindustrial processes (e.g., olive pomace) may be a good practice for increasing quality and sustainability of dairy products in regions less suited to the production of fodder. Finally, the valorization of waste biomass as feed is an interesting solution to its disposal, especially in areas where these by-products are produced in high amounts during short periods of the year.

\section{ACKNOWLEDGMENTS}

This research is part of the project "PROmozione della Salute del consumatore: valorizzazione nutriz- 
ionale dei prodotti agroalimentari della tradizione italiana (ProS.IT)" financially supported by Ministero dell'Istruzione dell'Università e della Ricerca. The authors are grateful to Cooperativa AN.SA.PE (L'Aquila, Italy) and Fausto Ruscitti (Cooperativa AN.SA.PE) for their kind cooperation.

\section{REFERENCES}

Abbeddou, S., B. Rischkowsky, M. E. D. Hilali, H. D. Hess, and M. Kreuzer. 2011a. Influence of feeding Mediterranean food industry by-products and forages to Awassi sheep on physicochemical properties of milk, yoghurt and cheese. J. Dairy Res. 78:426-435.

Abbeddou, S., B. Rischkowsky, E. K. Richter, H. D. Hess, and M. Kreuzer. 2011b. Modification of milk fatty acid composition by feeding forages and agro-industrial byproducts from dry areas to Awassi sheep. J. Dairy Sci. 94:4657-4668.

AOAC International. 1995. Official Methods of Analysis. 16th ed AOAC International, Washington, DC.

AOAC International. 2000. Official Methods of Analysis. 17th ed. AOAC International, Arlington, VA.

Awawdeh, M. S., and B. S. Obeidat. 2013. Treated olive cake as a non-forage fiber source for growing Awassi lambs: Effects on nutrient intake, rumen and urine $\mathrm{pH}$, performance, and carcass yield. Asian-australas. J. Anim. Sci. 26:661-667.

Basiricò, L., P. Morera, D. Dipasquale, A. Tröscher, and U. Bernabucci. 2017. Comparison between conjugated linoleic acid and essential fatty acids in preventing oxidative stress in bovine mammary epithelial cells. J. Dairy Sci. 100:2299-2309.

Basiricò, L., P. Morera, D. Dipasquale, A. Tröscher, A. Serra, M. Mele, and U. Bernabucci. 2015. Conjugated linoleic acid isomers strongly improve the redox status of bovine mammary epithelial cells (BME-UV1). J. Dairy Sci. 98:7071-7082.

Belury, M. A., A. Mahon, and S. Banni. 2003. The conjugated linoleic acid (CLA) isomer, t10c12-CLA, is inversely associated with changes in body weight and serum leptin in subjects with type 2 diabetes mellitus. J. Nutr. 133:257S-260S.

Bendall, J. G. 2001. Aroma compounds of fresh milk from New Zealand cows fed different diets. J. Agric. Food Chem. 49:4825-4832.

Branciari, R., D. Ranucci, M. Trabalza-Marinucci, M. Codini, M. Orru, R. Ortenzi, and A. Valiani. 2014. Evaluation of the antioxidant properties and oxidative stability of Pecorino cheese made from the raw milk of ewes fed Rosmarinus officinalis L. leaves. Int. J. Food Sci. Technol. 50:558-565.

Cais-Sokolińska, D., M. Majcher, J. Pikul, S. Bielińska, M. Czauderna and J. Wójtowski. 2011. The effect of Camelina sativa cake diet supplementation on sensory and volatile profiles of ewe's milk. Afr. J. Biotechnol. 10:7245-7252.

Caputo, A. R., G. Morone, M. A. Di Napoli, D. Rufrano, E. Sabia, F. Paladino, L. Sepe, and S. Claps. 2015. Effect of destoned olive cake on the aromatic profile of cows' milk and dairy products: Comparison of two techniques for the headspace aroma profile analysis. Ital. J. Agron. 10:15-20.

Chilliard, Y., and A. Ferlay. 2004. Dietary lipids and forages interactions on cow and goat milk fatty acid composition and sensory properties. Reprod. Nutr. Dev. 44:467-492.

Chiofalo, B., L. Liotta, A. Zumbo, and V. Chiofalo. 2004. Administration of olive cake for ewe feeding: Effect on milk yield and composition. Small Rumin. Res. 55:169-176.

Cibik, M., and G. Keles. 2016. Effect of stoned olive cake on milk yield and composition of dairy cows. Rev. Med. Vet. 167:154-158.

Curioni, P. M. G., and J. O. Bosset. 2002. Key odorants in various cheese types as determined by gas chromatography-olfactometry. Int. Dairy J. 12:959-984.

Day, E. A. 1966. Role of milk lipids in flavors of dairy products. Pages 94-120 in Flavor Chemistry. Vol. 56. I. Hornstein, ed. Am. Chem. Soc. Editorial Library, Washington, DC.
Dhiman, T. R., L. D. Satter, M. W. Pariza, M. P. Galli, K. Albright, and M. X. Tolosa. 2000. Conjugated linoleic acid (CLA) content of milk from cows offered diets rich in linoleic and linolenic acid. J. Dairy Sci. 83:1016-1027.

Dilzer, A., and Y. Park. 2012. Implication of conjugated linoleic acid (CLA) in human health. Crit. Rev. Food Sci. Nutr. 52:488-513.

Domagała, J., M. Sady, T. Grega, H. Pustkowiak, and A. Florkiewicz. 2010. The influence of cheese type and fat extraction method on the content of conjugated linoleic acid. J. Food Compos. Anal. $23: 238-243$.

Elmore, J. S. S. L. Cooper, M. Enser, D. S. Mottram, L. A. Sinclair, R. G. Wilkinson, and J. D. Wood. 2005. Dietary manipulation of fatty acid composition in lamb meat and its effect on the volatile aroma compounds of grilled lamb. Meat Sci. 69:233-242.

Esterbauer, H. 1982. Aldehydic products of lipid peroxidation. Pages 101-128 in Free Radicals, Lipid Peroxidation and Cancer. D. C. H. McBrien and T. F. Slater, ed. Academic Press, London, UK.

European Economic Community. 1986. EEC Council Directive 86/609/EEC of 24 November 1986 on the approximation of laws, regulations and administrative provisions of the Member States regarding the protection of animals used for experimental and other scientific purposes. Off. J. Eur. Union L 358:1-28.

European Union. 2010. Directive 2010/63/EU of the European parliament and of the council of 22 September 2010 on the protection of animals used for scientific purposes. Accessed Apr. 3, 2015. http:// eur-lex.europa.eu/legal-content/EN/TXT/PDF/?uri=CELEX: 32010 L0063\&from $=$ EN.

Evans, M. E., J. M. Brown, and M. K. McIntosh. 2002. Isomer-specific effects of conjugated linoleic acid (CLA) on adiposity and lipid metabolism. J. Nutr. Biochem. 13:508-516.

Goering, H. K., and P. J. Van Soest. 1970. Forage Fiber Analyses (Apparatus, Reagents, Procedures, and Some Applications). Agric. Handbook No. 379. ARS-USDA, Washington, DC.

Gómez-Cortés, P., P. Frutos, A. R. Mantecón, M. Juárez, M. A. De La Fuente, and G. Hervás. 2008. Addition of olive oil to dairy ewe diets: Effect on milk fatty acid profile and animal performance. J. Dairy Sci. 91:3119-3127.

Griinari, J. M., B. A. Corl, S. H. Lacy, P. Y. Chouinard, K. V. V Nurmela, and D. E. Bauman. 2000. Conjugated linoleic acid is synthesized endogenously in lactating dairy cows by $\Delta^{9}$-desaturase. J. Nutr. 130:2285-2291.

Griinari, J. M., D. A. Dwyer, M. A. McGuire, D. E. Bauman, D. L. Palmquist, and K. V. Nurmela. 1998. Trans-octadecenoic acids and milk fat depression in lactating dairy cows. J. Dairy Sci. 81:1251-1261.

Jenkins, T. C., A. A. Abu Ghazaleh, S. Freeman, and E. J. Thies. 2006. The production of 10-hydroxystearic and 10-ketostearic acids is an alternative route of oleic acid transformation by the ruminal microbiota in cattle. J. Nutr. 136:926-931.

Jenkins, T. C., and M. A. McGuire. 2006. Major advances in nutrition: Impact on milk composition. J. Dairy Sci. 89:1302-1310.

Kramer, J. K., M. Hernandez, C. Cruz-Hernandez, J. Kraft, and M. E. Dugan. 2008. Combining results of two GC separations partly achieves determination of all cis and trans 16:1, 18:1, 18:2 and 18:3 except CLA isomers of milk fat as demonstrated using Ag-ion SPE fractionation. Lipids 43:259-273.

Liu, S. Q., R. Holland, and V. L. Crow. 2004. Esters and their biosynthesis in fermented dairy products: A review. Int. Dairy J. 14:923-945.

Lock, A. L., and D. E. Bauman. 2004. Modifying milk fat composition of dairy cows to enhance fatty acids beneficial to human health. Lipids 39:1197-1206.

Lock, A. L., B. A. Corl, D. M. Barbano, D. E. Bauman, and C. Ip. 2004. The anticarcinogenic effect of trans-11 18:1 is dependent on its conversion to cis-9, trans-11 CLA by $\Delta^{9}$-desaturase in rats. J. Nutr. 134:2698-2704.

Loften, J. R., J. G. Linn, J. K. Drackley, T. C. Jenkins, C. G. Soderholm, and A. F. Kertz. 2014. Invited review: Palmitic and stearic acid metabolism in lactating dairy cows. J. Dairy Sci. 97:46614674 . 
Mariani, P., P. Bonatti and S. Sandri. 1992. Variazioni del contenuto in urea del latte e del suo rapporto con il contenuto di azoto non proteico. L'industria del latte. 28:1, 3.

Marone, E., A. Rotundo, N. Lombardo, E. Perri, and P. Fiorino. 2003. Fruit growth and evolution of oil accumulation in the cultivar "Maiatica di Ferrandina" in two environments of the Basilicata Region. Pages 178-186 in Proc. Int. Symp. on the Olive Tree and Environment, Chania, Greece. E. Stefanoudaki, ed. MAICh, Crete, Greece.

McSweeney, P. L. H., and M. J. Sousa. 2000. Biochemical pathways for the production of flavour compounds in cheeses during ripening: A review. Lait 80:293-324.

Mele, M., G. Conte, B. Castiglioni, S. Chessa, N. P. P. Macciotta, A. Serra, A. Buccioni, G. Pagnacco, and P. Secchiari. 2007. Stearoylcoenzyme A desaturase gene polymorphism and milk fatty acid composition in Italian Holsteins. J. Dairy Sci. 90:4458-4465.

Mele, M., A. Serra, A. Buccioni, G. Conte, A. Pollicardo, and P. Secchiari. 2008. Effect of soybean oil supplementation on milk fatty acid composition from Saanen goats fed diets with different forage: concentrate ratios. Ital. J. Anim. Sci. 7:297-311.

Mele, M., A. Serra, M. Pauselli, G. Luciano, M. Lanza, P. Pennisi, G. Conte, A. Taticchi, S. Esposto, and L. Morbidini. 2014. The use of stoned olive cake and rolled linseed in the diet of intensively reared lambs: Effect on the intramuscular fatty-acid composition. Animal 8:152-162.

Moate, P. J., S. R. O. Williams, V. A. Torok, M. C. Hannah, B. E. Ribaux, M. H. Tavendale, R. J. Eckard, J. L. Jacobs, M. J. Auldist, and W. J. Wales. 2014. Grape marc reduces methane emissions when fed to dairy cows. J. Dairy Sci. 97:5073-5087.

Moio, L., D. Langlois, P. Etievant, and F. Addeo. 1993. Powerful odorants in bovine, ovine, caprine and water buffalo milk determined by means of gas chromatography-olfactometry. J. Dairy Res. 60:215-222.

Molina-Alcaide, E., and P. R. Yañez-Ruiz. 2008. Potential use of olive by products in ruminant feeding: A review. Anim. Feed Sci. Technol. 147:247-264.

Mosley, E. E., G. L. Powell, M. B. Riley, and T. C. Jenkins. 2002. Microbial biohydrogenation of oleic acid to trans isomers in vitro. J. Lipid Res. 43:290-296.

Mosley, E. E., B. Shafii, P. J. Moate, and M. A. McGuire. 2006. Cis-9, trans-11 conjugated linoleic acid is synthesized directly from vaccenic acid in lactating dairy cattle. J. Nutr. 136:570-575.

Mozaffarian, D., R. Micha, and S. Wallace. 2010. Effects on coronary heart disease of increasing polyunsaturated fat in place of saturated fat: A systematic review and meta-analysis of randomized controlled trials. PLoS Med. 7:e1000252.

Nudda, A., M. A. McGuire, G. Battacone, and G. Pulina. 2005. Seasonal variation in conjugated linoleic acid and vaccenic acid in milk fat of sheep and its transfer to cheese and ricotta. J. Dairy Sci. 88:1311-1319.

Owaimer, A. N., M. S. Kraidees, M. Al-saiady, S. Zahran, and M. A. Abouheif. 2004. Effect of feeding olive cake in complete diet on performance and nutrient utilization of lambs. Asian-australas. J. Anim. Sci. 17:491-496.

Ozturkoglu-Budak, S., A. Gursoy, D. P. Aykas, C. Koçak, S. Dönmez, R. P. De Vries, and P. A. Bronll. 2016. Volatile compound of Turkish Divle Cave cheese during production and ripening. J. Dairy Sci. 99:5120-5131.
Pallara, G., A. Buccioni, R. Pastorelli, S. Minieri, M. Mele, S. Rapaccini, A. Messini, M. Pauselli, M. Servili, L. Giovannetti, and C. Viti. 2014. Effect of stoned olive pomace on rumen microbial communities and polyunsaturated fatty acid biohydrogenation: An in vitro study. BMC Vet. Res. 10:271.

Platt, I., L. G. Rao, and A. El-Sohemy. 2007. Isomer-specific effects of conjugated linoleic acid on mineralized bone nodule formation from human osteoblast-like cells. Exp. Biol. Med. (Maywood) $232: 246-252$

Sadeghi, H., A. Teimouri Ynsari, and Z. Ansari-Pirsarai. 2009. Effects of different olive cake by products on dry matter intake, nutrient digestibility and performance of Zel sheep. Int. J. Agric. Biol. 11:39-43.

Shingfield, K. J., M. Bonnet, and N. D. Scollan. 2013. Recent developments in altering the fatty acid composition of ruminant-derived foods. Animal 7(Suppl. 1):132-162

Sinclair, L. A. 2007. Nutritional manipulation of the fatty acid composition of sheep meat: A review. J. Agric. Sci. 145:419-434.

Smit, B. A. 2004. Formation of amino acid derived cheese flavour compounds. PhD Thesis. Wageningen University, Wageningen, the Netherlands.

Smith, S. B., D. K. Lunt, K. Y. Chung, C. B. Choi, R. K. Tume, and M. Zembayashi. 2006. Adiposity, fatty acid composition, and delta-9 desaturase activity during growth in beef cattle. Anim. Sci. J. $77: 478-486$.

Song, H. J., I. Grant, D. Rotondo, I. Mohede, N. Sattar, S. D. Heys, and K. W. J. Wahle. 2005. Effect of CLA supplementation on immune function in young healthy volunteers. Eur. J. Clin. Nutr. 59:508-517.

Sundram, K., M. A. French, and M. T. Clandinin. 2003. Exchanging partially hydrogenated fat for palmitic acid in the diet increases LDL-cholesterol and endogenous cholesterol synthesis in normocholesterolemic women. Eur. J. Nutr. 42:188-194.

Sympoura, F., A. Cornu, P. Tournayre, T. Massouras, J. L. Berdagué and B. Martin. 2009. Odor compounds in cheese made from the milk of cows supplemented with extruded linseed and $\alpha$-tocopherol. J. Dairy Sci. 92:3040-3048.

Terramoccia, S., S. Bartocci, A. Taticchi, S. Di Giovanni, M. Pauselli, E. Mourvaki, S. Urbani, and M. Servili. 2013. Use of dried stoned olive pomace in the feeding of lactating buffaloes: Effect on the quantity and quality of the milk produced. Asian-australas. J. Anim. Sci. 26:971-980.

Ulbricht, T. L. V., and D. A. T. Southgate. 1991. Coronary heart disease: Seven dietary factors. Lancet 338:985-992.

Vargas-Bello-Pérez, E., R. R. Vera, C. Aguilar, R. Lira, I. Peña, and J. Fernández. 2013. Feeding olive cake to ewes improves fatty acid profile of milk and cheese. Anim. Feed Sci. Technol. 184:94-99.

Vasta, V., D. R. Yáñez-Ruiz, M. Mele, A. Serra, G. Luciano, M. Lanza, L. Biondi, and A. Priolo. 2010. Bacterial and protozoal communities and fatty acid profile in the rumen of sheep fed a diet containing added tannins. Appl. Environ. Microbiol. 76:2549-2555.

Walker, N. J., S. Patton, and P. S. Dimick. 1968. Incorporation of $[1-14 \mathrm{C}]$ acetate into the aliphatic $\delta$-lactones of ruminant milk fat. Biochim. Biophys. Acta 152:445-453.

Zilio, D. M., S. Bartocci, S. Di Giovanni, M. Servili, A. Chiariotti, and S. Terramoccia. 2014. Evaluation of dried stoned olive pomace as supplementation for lactating Holstein cattle: Effect on milk production and quality. Anim. Prod. Sci. 55:185-188. 